\title{
Bur open Meteorological factors and risk of community-acquired Legionnaires' disease in Switzerland: an epidemiological study
}

\author{
Lisa Conza, ${ }^{1}$ Simona Casati, ${ }^{1}$ Costanzo Limoni, ${ }^{2}$ Valeria Gaia ${ }^{1}$
}

To cite: Conza L, Casati S, Limoni C, et al.

Meteorological factors and risk of community-acquired Legionnaires' disease in

Switzerland: an

epidemiological study. BMJ Open 2013;3:e002428.

doi:10.1136/bmjopen-2012002428

- Prepublication history for this paper are available online. To view these files please visit the journal online (http://dx.doi.org/10.1136/ bmjopen-2012-002428)

Received 30 November 2012 Revised 17 January 2013 Accepted 31 January 2013

This final article is available for use under the terms of the Creative Commons Attribution Non-Commercial 2.0 Licence; see http://bmjopen.bmj.com

${ }^{1}$ Swiss National Reference Centre for Legionella, Cantonal Institute of Microbiology, Bellinzona, Switzerland

${ }^{2}$ Alpha5, Biometrics \& Data Management, Riva San Vitale, Switzerland

Correspondence to Dr Lisa Conza; lisa.conza@ti.ch

\section{ABSTRACT}

Objectives: The aim of this study was to identify meteorological factors that could be associated with an increased risk of community-acquired Legionnaires' disease (LD) in two Swiss regions.

Design: Retrospective epidemiological study using discriminant analysis and multivariable Poisson regression.

Setting: We analysed legionellosis cases notified between January 2003 and December 2007 and we looked for a possible relationship between incidence rate and meteorological factors.

Participants: Community-acquired LD cases in two Swiss regions, the Canton Ticino and the Basle region, with climatically different conditions were investigated.

Primary outcome measures: Vapour pressure, temperature, relative humidity, wind, precipitation and radiation recorded in weather stations of the two Swiss regions during the period January 2003 and December 2007.

Results: Discriminant analysis showed that the two regions are characterised by different meteorological conditions. A multiple Poisson regression analysis identified region, temperature and vapour pressure during the month of infection as significant risk factors for legionellosis. The risk of developing LD was $129.5 \%$ (or $136.4 \%$ when considering vapour pressure instead of temperature in the model) higher in the Canton Ticino as compared to the Basle region. There was an increased relative risk of LD by $11.4 \%(95 \% \mathrm{Cl}$ $7.70 \%$ to $15.30 \%$ ) for each $1 \mathrm{hPa}$ rise of vapour pressure or by $6.7 \%(95 \% \mathrm{Cl} 4.22 \%$ to $9.22 \%)$ for $1^{\circ} \mathrm{C}$ increase of temperature.

Conclusions: In this study, higher water vapour pressure and heat were associated with a higher risk of community-acquired LD in two regions of Switzerland.

\section{INTRODUCTION}

Bacteria of the genus Legionella colonise natural and man-made aquatic environments, soils or free-living amoebae. ${ }^{1}$ Some species may cause Legionnaires' disease (LD) and Pontiac fever. ${ }^{2}$ Transmission occurs by

\section{ARTICLE SUMMARY}

Article focus

- Identify meteorological factors that could be associated with an increased risk of community-acquired Legionnaires' disease (LD) in two Swiss regions.

- A link between community-acquired LD and warm, humid weather is established. However, the risk factors and epidemiology of LD are not well understood.

- Compare two different regions (with different climatic conditions) and include vapour pressure for $L D$ infection risk.

\section{Key messages}

- In Switzerland, there was an increased relative risk of LD of $11.4 \%$ (95\% $\mathrm{Cl} 7.70 \%$ to $15.30 \%)$ for each $1 \mathrm{hPa}$ rise of vapour pressure or of $6.7 \%(95 \% \mathrm{Cl} 4.22 \%$ to $9.22 \%)$ for $1^{\circ} \mathrm{C}$ increase of temperature.

- In the southern Swiss region of canton Ticino, the incidence during the period 2003-2007 was three times higher than in the northern Swiss region. Our model revealed that the region also has an influence on the incidence of LD.

Strengths and limitations of the study

- The originality of this study is to use vapour pressure as a variable instead of relative humidity for multivariable Poisson regression analysis to identify the main risk factors of the weather for LD.

- The main limitation of this study is the use of monthly mean of the month during which the LD case occurred because the incubation period of 14 days for every case cannot be exactly determined.

inhalation of contaminated bioaerosols, generated by the aerosolisation of water droplets from different reservoirs, such as airconditioning units, ${ }^{3}{ }^{4}$ cooling towers, ${ }^{5}$ whirlpool spas, ${ }^{6}$ soils, ${ }^{7}$ sink taps and showerheads. ${ }^{8}$

The incidence of LD in Europe during the period 2003-2007 amounted to 1-1.3 cases per 100000 inhabitants per year with a case death of $6.6 \% .^{2}$ In Switzerland, in the same 
period, the incidence was about 2-2.5 cases per 100000 inhabitants per year, with a case death of about $7.1 \% .^{9}$ In the southern Swiss region of Canton Ticino, however, the incidence was three times higher (approximately $6 / 100000) .{ }^{9}$ In Switzerland, community-acquired LD cases are not randomly distributed. So far, it is not clear why the incidence is so high in southern Switzerland and the sources of Legionella infections could rarely be identified.

Switzerland is divided into two parts by the Alps, with the mountains acting as a barrier that creates two distinct climatic zones. ${ }^{10}$ The northern part is characterised by rigid, rather dry winters and warm summers with frequent precipitations. The climatic conditions in the South are influenced by the geography, with lakes that favour dry and mild winters with a very low relative humidity. The summers are normally hot, with heavy thunderstorms and short, heavy spells of precipitations that with lake water evaporation (most likely influenced by local geography) contribute to the rising vapour pressure in the air. ${ }^{11}$

Previous studies showed that the warm, wet weather and rainfalls were associated with an increased risk for legionellosis. ${ }^{12-14}$ Therefore, in Switzerland, the climate could play an important role in the transmission of LD from sources located within the community.

The aim of this study was to investigate whether or not the occurrence of community-acquired LD could be associated with specific meteorological factors (such as temperature, relative humidity, vapour pressure, wind, radiation and precipitation) during the month of occurrence of the disease in two different Swiss regions characterised by two distinct climatic conditions.

\section{METHODS}

Study area and design

The Canton Ticino ('Ticino') and the region of Basle (Basle: cantons Basel-Stadt, Basel-Land, Aargau and Solothurn) were chosen to estimate the risk of occurrence of legionellosis. The Canton Ticino is located in southern Switzerland and is a mountainous region with valleys and lakes, as opposed to the region of Basle, located in the north-western part of the country on the Swiss Plateau, which is an almost flat region, covered with rolling hills, lakes and rivers. The climate in Canton Ticino is generally very warm in the summer, with some days of very high humidity. ${ }^{10}$ The northern region was chosen to have a higher LD incidence than other Swiss cantons and thus to be comparable to Canton Ticino. Moreover, this group of cantons was chosen due to their similar geography, population characteristics and proportion of urban/rural territory.

\section{Case identification}

We defined a case of a patient with a laboratory-confirmed case of LD when, in addition to the clinical diagnosis of pneumonia, at least one of the following criteria were met:
(1) isolation in culture and identification of Legionella in secretions from the respiratory tract, lung tissue or blood; (2) at least a fourfold increase in antibody titre against Legionella pneumophila serogroup 1 and (3) detection of specific L pneumophila antigen in urine. ${ }^{9}$

Only autochthonous cases with sporadic communityacquired LD, for which a travel-associated or nosocomial origin could be excluded and for which the date of onset was known and occurred between 1 January 2003 and 31 December 2007, were included in the study.

\section{Data collection}

Meteorological data were obtained from three main weather stations in Ticino (covering the most populated areas) and two in Basle. The meteorological data evaluated in this investigation were the monthly means of daily average relative humidity, vapour pressure, mean temperature, global radiation, daily amount of precipitations, wind speed and occurrence of strong, warm winds in the Alps (Foehn). ${ }^{10}$ We defined Foehn as a dry, relatively warm downslope wind that occurs either in the north or south lee of the Alps.

Information on sporadically occurring, communityacquired cases (date of onset, age and sex of the patients) of the two regions were provided by the Swiss Federal Office of Public Health (FOPH).

\section{Data analysis}

\section{Discriminant analysis}

A canonical discriminant analysis was performed to assess differences in meteorological conditions between the two regions. The analysis was carried out using monthly means of daily average data for relative humidity, vapour pressure, mean temperature, global radiation, wind speed and daily amount of precipitations recorded in Ticino and Basle. The analysis was carried out with SPSS V.17.0 (SPSS Inc, Chicago, Illinois, USA).

\section{Multivariable Poisson regression}

A multivariable Poisson regression was used to identify the main risk factors for LD. The cases are the prevalence of LD per 100000 inhabitants grouped by month of onset and for each meteorological variable, a monthly average was calculated using data from the closest weather station. For those months with no case reported, the monthly mean of each variable was used in the model.

A preliminary analysis indicated that the model constructed using contemporaneously both temperature and vapour pressure suffered from collinearity problems, because the correlations between vapour pressure and average temperature, and vapour pressure and minimal and maximal temperature were almost $100 \%$ $(\mathrm{r}>0.96)$. Thus, we first carried out two separate multiple Poisson regression models: the first included average temperatures but no vapour pressure, while the second considered vapour pressure but no temperature data. Both models included additionally relative humidity, 
vapour pressure, radiation, Foehn, wind speed, precipitation and year as independent variables.

The final model included only those variables that reached a $p$ value of $<0.05$ in the preliminary model with all the variables. To quantify the effects of meteorological variables, we computed the influences $\left(e^{\beta}-1\right)$, which virtually correspond to the relative risks. These analyses were carried out using SAS (V.8.01, SAS Institute, Cary, New Jersey, USA). Data are presented as relative risk and corresponding $95 \%$ CI. $p$ values $<0.05$ were considered statistically significant. Goodness of fit (GOF) of the final model was tested using the GOF $\chi$-square test applied to the deviance values shown in the SAS output.

\section{RESULTS}

\section{Demographics}

About $17.8 \%$ of the patients were over 64 years of age and two thirds were male patients. Between 2003 and 2007, 101 cases of community-acquired LD were reported in Ticino and 154 in Basle. The number of cases fluctuates and follows seasonality; more events are reported in spring and summer (April-September; figure 1). The populations of the two regions are very similar in their characteristics and the underlying conditions were not included in the models; for example, in 2007, the proportion of women was $52 \%$ in Ticino and $50.8 \%$ in Basle region; there were $19.7 \%$ persons aged over 64 in Ticino and $16.8 \%$ in Basle region, respectively.

\section{Meteorological characterisation of the two regions studied}

Canonical discriminant analysis carried out using daily average data for relative humidity, vapour pressure, mean temperature, global radiation, wind speed and daily amount of precipitations revealed that the Basle data can be grouped consistently according to their meteorological characteristics and were well separated from the Ticino data (figure 2). The first three canonical discriminant functions explain $95.8 \%$ of the variance of the model. When the four cantons grouped in the Basle region were considered separately, the predictive values based on the new canonical variables were only moderately concordant with the original grouping, because only $53.3 \%$ of all cases were correctly classified in their original categories (table 1). The two regions, Ticino and Basle, however, could be clearly separated, with $91 \%$ of the cases correctly classified. Thus, discriminant analysis has confirmed that the two regions investigated have clearly distinct climatic situations, with the four northern cantons being meteorologically quite similar. The most important variable that influenced the first function of the model was the temperature; vapour pressure was determining the second and third functions.

\section{Influence of meteorological factors on LD}

The study of correlations between the independent variables at the regional and global levels revealed a nearly perfect correlation $(r>0.96)$ between vapour pressure and average temperature, and vapour pressure and minimal and maximal temperature. Therefore, to avoid collinearity problems, we decided to explore the relationship of temperature and vapour pressure with LD cases by using two different models, including either temperature or vapour pressure together with all other predictors. In the two models, temperature $(p=0.0002)$ and vapour pressure $(\mathrm{p}=0.0014)$ were highly significant; year and region were also significant in both models (table 2).

The final model showed that vapour pressure and temperature, respectively, are highly significant factors that influence the risk of LD (both $\mathrm{p}<0.0001)$. Each $1 \mathrm{hPa}$ raise of vapour pressure corresponds to an increase in the number of cases by $11.4 \%$ (95\% CI $7.70 \%$ to $15.30 \%$ ); likewise, a raise of $1{ }^{\circ} \mathrm{C}$ corresponds to an increase of $6.7 \%$ (95\% CI $4.22 \%$ to $9.22 \%$ ). The results show that in Ticino the risk of being infected by Legionella is much higher than in Basle $(129.5 \%$ or $136.4 \%$, depending on the variable considered in the model; see table 2). The variable year is also significant using either vapour pressure $(\mathrm{p}=0.0034)$ or temperature $(\mathrm{p}=0.0073)$ as independent variables. During the period 2003-2007, the relative risk of LD has been increasing in both the regions at an annual rate of approximately $16 \%$, after adjusting by region and vapour pressure or temperature effect (table 2).

\section{DISCUSSION}

Our study indicates that temperature and vapour pressure during the month of disease are the meteorological factors that most influence the occurrence of sporadic community-acquired LD.

The two regions studied, Ticino and Basle, can be distinguished using meteorological parameters. Multiple Poisson regression identified vapour pressure and temperature as important contributing factors influencing the occurrence of legionellosis in both regions.

Association of weather factors with legionellosis has been described in previous studies that identified relative humidity and temperature as the most important risk for infection, ${ }^{12}{ }^{13} 15$ but to date the role of vapour pressure has not been investigated.

The relative humidity is the ratio of the partial pressure of water vapour in the air-water mixture to the saturated vapour pressure of water at the same conditions of temperature and pressure. Thus, relative humidity explains how far the air is from a saturated condition. In contrast, the vapour pressure is the measure of the partial pressure of water vapour in the air-water mixture saturated with water and decreases non-linearly with temperature. ${ }^{12}$ Vapour pressure increases with increasing relative humidity.

Our analysis indicates that vapour pressure is the most important factor that influences the increase in a number of cases of legionellosis in both the regions. 
Figure 1 Seasonal distribution and incidence of Legionnaires' disease cases according to onset date in Ticino and Basle from 2003 to $2007 .^{9} \mathrm{~W}$ : winter (October-March), S: summer (April-September).

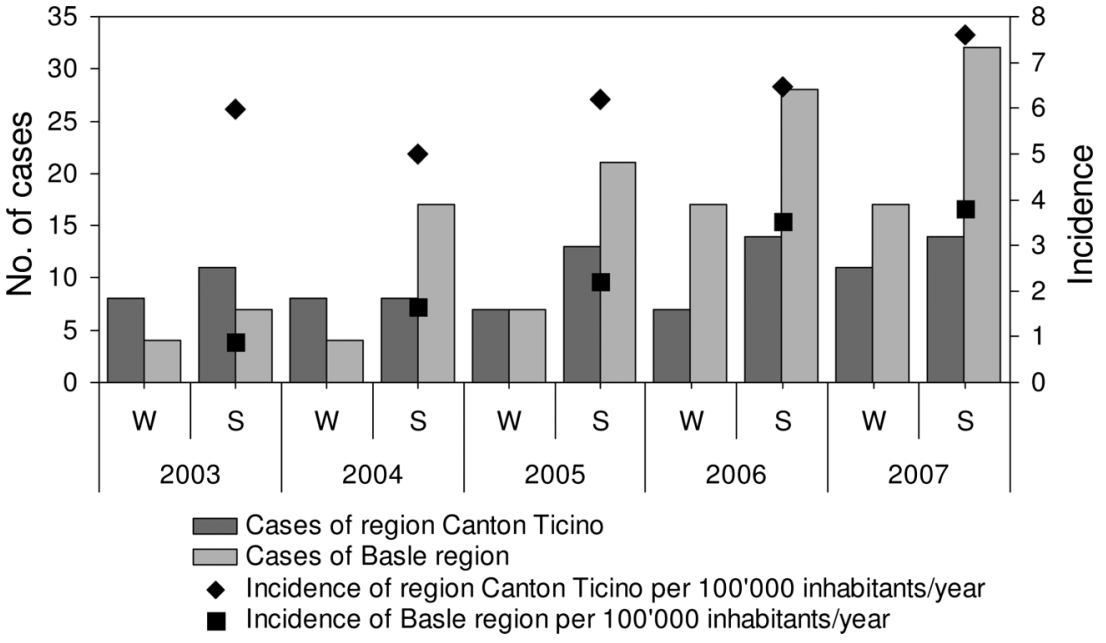

The two regions investigated in this study differ from each other in their geographic and climatic features. Summers in Ticino are characterised by days with very high vapour pressure, for example, after thunderstorms, ${ }^{11}$ as opposed to the northern Swiss regions. ${ }^{10}$ In general, throughout the year, the relative humidity is higher and the temperature is lower in Basle as compared to Ticino. By contrast, the vapour pressure is higher in Ticino than in Basle during summer. ${ }^{10}$

In Ticino, the risk of being infected is much higher than in Basle; this is confirmed by the much higher incidence of cases in Ticino than in northern Switzerland. The risk of being infected in Canton Ticino rises by $11.4 \%$ for each $1 \mathrm{hPa}$ increase in vapour pressure: this is in accordance with clinical observations that set the highest incidence of LD in the summer months, when in Ticino the vapour pressure is higher (eg, the monthly mean of August 2007 for Ticino was $16.9 \mathrm{hPa}$ vs 15.2 hPa of region Basle). ${ }^{10}$

LD in Switzerland exhibits a strong seasonality, with a summer-early autumn increase of notified LD cases, as noted also in the USA ${ }^{13-15}$ and Europe. ${ }^{16}{ }^{17}$ No cases were
Figure 2 Graphical plot of the discriminant model. The centroids of the data of Basle (1-4) are grouped and well separated from Ticino (5). In total, $95.8 \%$ of the total variance are explained by the first tree discriminant functions.

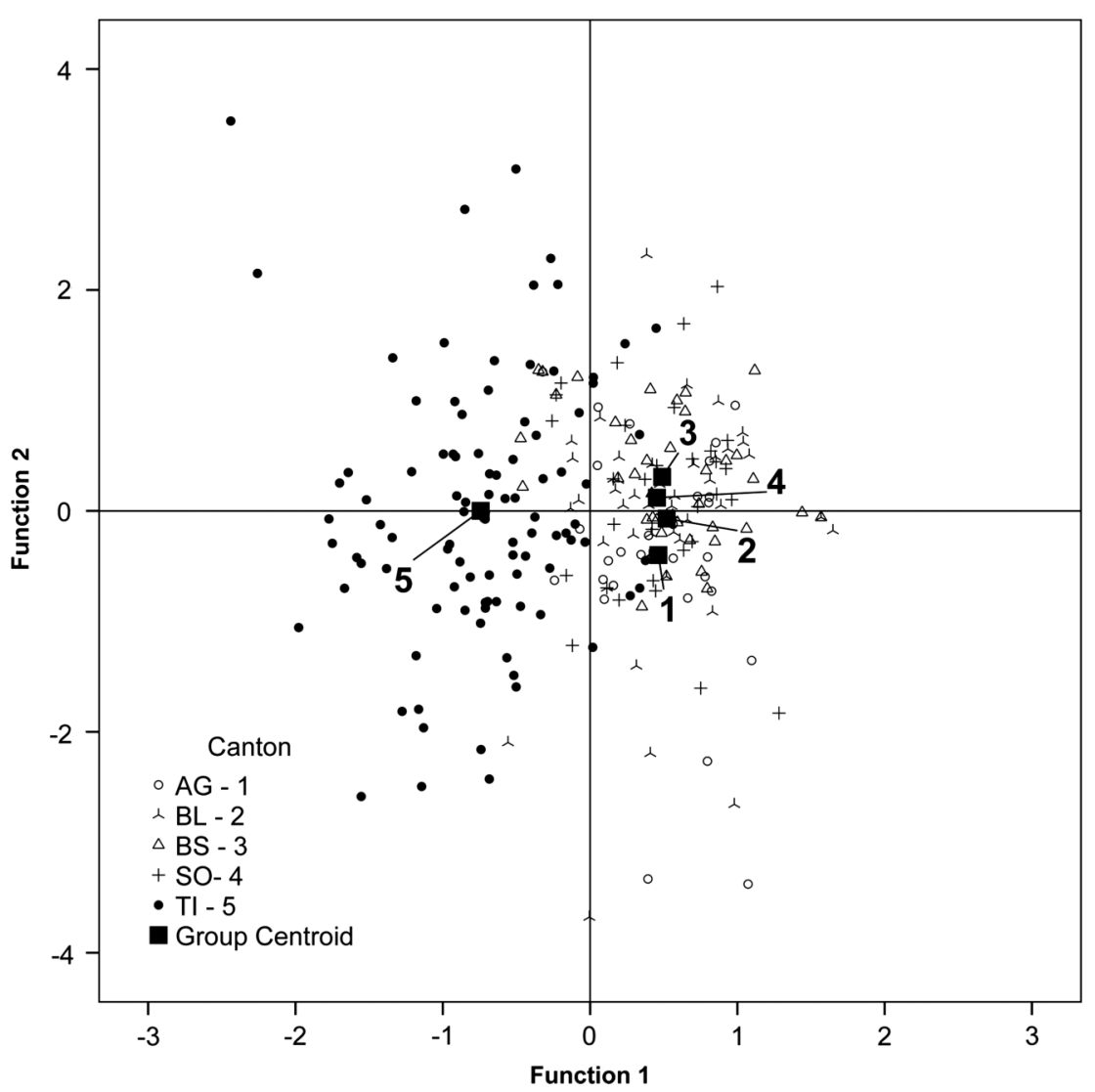


Table 1 Classification of results

\begin{tabular}{|c|c|c|c|c|c|c|}
\hline \multirow{2}{*}{ Region } & \multirow[b]{2}{*}{ Canton } & \multicolumn{5}{|c|}{ Predicted group membership (\%) } \\
\hline & & Aargau & Basel-Land & Basel-Stadt & Solothurn & Ticino \\
\hline \multirow[t]{4}{*}{ Basle } & Aargau & 12.5 & 65.6 & 6.3 & 6.3 & 9.3 \\
\hline & Basel-Land & 4.0 & 70.0 & 2.0 & 14.0 & 10.0 \\
\hline & Basel-Stadt & 2.5 & 60.0 & 5.0 & 15.0 & 17.5 \\
\hline & Solothurn & 0.0 & 65.6 & 9.4 & 9.4 & 15.6 \\
\hline Ticino & Ticino & 1.0 & 3.0 & 4.0 & 1.0 & 91 \\
\hline
\end{tabular}

In total, $53.3 \%$ of original grouped cases correctly reclassified.

Numbers in bold show that four Cantons are very similar and form a group that could be differentiated from canton Ticino.

reported for 17 months in Ticino and for 12 months in the Basle region.

The number of LD cases notified in Switzerland is increasing yearly in both regions, as it is in the whole of Europe. ${ }^{2}$ This is the reason we inserted the variable year in the Poisson model to control for additional confounding, unknown factors and indeed, in both models, the variable year was highly significant.
Poisson regression models are often not suitable to study infectious diseases because of the non-independence of events caused by person-to-person transmission; it is, however, appropriate for LD because contagion occurs mainly through aerosol.

Some methodological limitations must be acknowledged for this study: the incubation period of 14 days for every case cannot be determined exactly and this is

Table 2 Poisson regression model of meteorological factor associated with risk of LD

\begin{tabular}{|c|c|c|c|}
\hline & $\beta$ & $\left(e^{\beta}-1\right)=R R(\%)$ & p Value \\
\hline \multicolumn{4}{|l|}{ (A) } \\
\hline Intercept & -356.746 & & 0.0027 \\
\hline Relative humidity & 0.0051 & 0.51 & 0.8161 \\
\hline Vapour pressure & 0.1220 & 12.98 & $0.0014^{\star}$ \\
\hline Region & 0.7665 & 115.22 & $0.0036^{\star}$ \\
\hline Radiation & -0.0011 & -0.11 & 0.7130 \\
\hline Foehn & -0.0189 & -1.87 & 0.4660 \\
\hline Wind & 0.0224 & 2.27 & 0.8311 \\
\hline Precipitation & 0.0260 & 2.63 & 0.3804 \\
\hline Year & 0.1766 & 19.32 & $0.0030^{\star}$ \\
\hline \multicolumn{4}{|l|}{ (B) } \\
\hline Intercept & -347.822 & & 0.0031 \\
\hline Relative humidity & 0.0189 & 1.91 & 0.3207 \\
\hline Temperature & 0.1036 & 10.92 & $0.0002^{*}$ \\
\hline Region & 0.7985 & 122.22 & $0.0021^{*}$ \\
\hline Radiation & -0.0030 & -0.30 & 0.3357 \\
\hline Foehn & -0.0193 & -1.91 & 0.4608 \\
\hline Wind & 0.0361 & 3.68 & 0.7329 \\
\hline Precipitation & 0.0272 & 2.76 & 0.3532 \\
\hline Year & 0.1717 & 18.73 & $0.0035^{\star}$ \\
\hline \multicolumn{4}{|l|}{ (C) } \\
\hline Intercept & -321.042 & & $0.0032^{*}$ \\
\hline Vapour pressure & 0.1083 & 11.44 & $<0.0001^{\star *}$ \\
\hline Region & 0.8603 & 136.39 & $<0.0001^{\star *}$ \\
\hline Year & 0.1587 & 15.87 & $<0.0034^{\star}$ \\
\hline \multicolumn{4}{|l|}{ (D) } \\
\hline Intercept & -299.281 & & $0.0069^{\star}$ \\
\hline Temperature & 0.0647 & 6.68 & $<0.0001^{\star *}$ \\
\hline Region & 0.8309 & 129.54 & $<0.0001^{\star *}$ \\
\hline Year & 0.1481 & 15.96 & $0.0073^{\star}$ \\
\hline
\end{tabular}


the reason we chose to use monthly mean of the month during which the LD case occurred; the use of aggregate or average meteorological data, which are approximations for each daily and monthly value or the aggregation of LD cases for months; the direction of these approximations, however, are likely to be random, suggesting that our risk estimates are reliable. Moreover, with this setup, we cannot evaluate the short-term effect of the weather on LD. We also used clinical data provided to the FOPH by several laboratories; we cannot exclude that our dataset can be incomplete because of the lack of case notifications or by missing or wrong bacterial identifications; undercounting of legionellosis cases, however, is a bias that should not influence the outcome of the analysis. Our study was performed only for the period 2003-2007 because more recent, updated data were not easily available. Finally, owing to this investigation being an ecological study, we cannot exclude that we could not identify and consider some potential confounding variables.

The population of the two regions is very similar in their characteristics and underlying conditions were not included in the models; for example, in 2007, the proportion of women was $52 \%$ in Ticino and $50.8 \%$ in Basle region; there were $19.7 \%$ persons aged over 64 in Ticino and $16.8 \%$ in Basle region, respectively. Legionellosis in Switzerland is more common in the age group between 70 and 79 years (23.4\% of reports), but the incidence is highest $(8.2 / 100000)$ in the age group over 80 years. About $40 \%$ of case patients are smokers and $15 \%$ of them showed advanced age (over 80 years) and diabetes. ${ }^{9}$

Che et $a l^{18}$ reported that the incidence of $\mathrm{LD}$ in France, on a small geographical scale, was associated with the presence of cooling towers in the vicinity of cases. Swiss cases are usually associated with urban centres, but the infection sources remain largely unknown. In 2003, Hohl and Steffen reported that Legionella isolates from cooling towers in Basle region are very similar to three clinical isolates. ${ }^{19}$ A survey performed in 2005 in Ticino identified 49 cooling towers of which only 29 could be sampled; $69 \%$ of them resulted in being heavily contaminated by Legionella, but no correlation between vicinity of cases and cooling towers could be established. ${ }^{20}$ Cooling towers could be the source exposures for LD in both regions.

In conclusion, high vapour pressure and temperature were associated with a higher risk of community-acquired LD in two regions of Switzerland, characterised by two distinct climatic conditions. These findings strongly support the hypothesis that climatic factors in general and vapour pressure and temperature in particular are risk factors for the transmission of community-acquired LD and should increase awareness of the increased risk of LD after days with humid and warm weather conditions.

Acknowledgements We thank the Federal Office of Meteorology and Climatology (MeteoSwiss) for kindly providing meteorological data. The financial support by Ticino Pulmonary League is gratefully acknowledged. PD Dr Orlando
Petrini (Cantonal Institute of Microbiology, Bellinzona) gave constructive advice, helped with the statistical analysis and read the manuscript critically.

Funding The work has been partially supported financially by the Ticino Pulmonary League.

Contributors All authors participated in the conception, design, analysis and interpretation of data. LC drafted the article; SC, VG and CL revised it critically for important intellectual content. All authors were involved in drafting and reviewing the manuscript and approved the final version.

Competing interests None.

Provenance and peer review Not commissioned; externally peer reviewed.

Data sharing statement No additional data are available.

\section{REFERENCES}

1. Fields BS, Benson RF, Besser RE. Legionella and Legionnaires' disease: 25 years of investigation. Clin Microbiol Rev 2002;15:506-26.

2. Joseph CA, Ricketts KD, On behalf of the European Working Group for Legionella Infections. Legionnaires' disease in Europe 20072008. Euro Surveill 2010;15:19493. http://www.eurosurveillance.org/ ViewArticle.aspx?Articleld=19493 (accessed 25 Feb 2012).

3. Fraser DW, Tsai TR, Orenstein W, et al. Legionnaires' disease: description of an epidemic of pneumonia. $N$ Engl J Med 1977;297:1189-97.

4. Lin $\mathrm{H}, \mathrm{Xu} \mathrm{B}, \mathrm{Chen} \mathrm{Y}$, et al. Legionella pollution in cooling tower water of air-conditioning systems in Shanghai, China. J Appl Microbiol 2009;106:606-12.

5. Ferre MR, Arias C, Oliva JM, et al. A community outbreak of Legionnaires' disease associated with a cooling tower in Vic and Gurb, Catalonia (Spain) in 2005. Eur J Clin Microbiol Infect Dis 2009;28:153-9.

6. Gotz HM, Tegnell A, De Jong B, et al. A whirlpool associated outbreak of Pontiac fever at a hotel in Northern Sweden. Epidemiol Infect 2001;126:241-7.

7. den Boer JW, Yzerman EP, Jansen R, et al. Legionnaires' disease and gardening. Clin Microbiol Infect 2007;13:88-91.

8. Bollin GE, Plouffe JF, Para MF, et al. Aerosols containing Legionella pneumophila generated by shower heads and hot-water faucets. Appl Environ Microbiol 1985;50:1128-31.

9. FOPH. Bericht Legionellen und Legionellose. Bern, Switzerland: Federal Office of Public Health FOPH, 2009.

10. MeteoSwiss. Swiss Climate. Federal Office of Metereology and Climatology Meteo Swiss, FDHA Switzerland. http://www. meteosvizzera.admin.ch/web/en/climate/swiss_climate.html (accessed 20 Oct 2012).

11. Telesca L, Kanevski M, Tonini M, et al. Temporal patterns of fire sequences observed in Canton of Ticino (southern Switzerland). Nat Hazard Earth Syst Sci 2010;10:723-8.

12. Amorim MF, Oliveira GH, Silva DS, et al. Water vapour partial pressure control in neonatal incubator using prevision by multiple models. Conf Proc IEEE Eng Med Biol Soc 2004;4:2356-9.

13. Fisman DN, Lim S, Wellenius GA, et al. It's not the heat, it's the humidity: wet weather increases legionellosis risk in the greater Philadelphia metropolitan area. J Infect Dis 2005;192:2066-73.

14. Hicks LA, Rose CE Jr, Fields BS, et al. Increased rainfall is associated with increased risk for legionellosis. Epidemiol Infect 2007;135:811-17.

15. $\mathrm{Ng} \mathrm{V}$, Tang $\mathrm{P}$, Jamieson $\mathrm{F}$, et al. Going with the flow: legionellosis risk in Toronto, Canada is strongly associated with local watershed hydrology. Ecohealth 2008;5:482-90.

16. Karagiannis I, Brandsema P, van der Sande M. Warm, wet weather associated with increased Legionnaires' disease incidence in the Netherlands. Epidemiol Infect 2009;137:181-7.

17. Bhopal RS, Fallon RJ. Seasonal variation of Legionnaires' disease in Scotland. J Infect 1991;22:153-60.

18. Che D, Decludt B, Campese C, et al. Sporadic cases of community acquired legionnaires' disease: an ecological study to identify new sources of contamination. J Epidemiol Community Health 2003;57:466-9.

19. Hohl P, Steffen I. Des tours aéroréfrigérantes sont-elles à l'origine de cas de légionellose? Observations faites à Bâle-Ville. Bull FOPH 2003;29:504.

20. Gaia V. Prévention de la légionellose: étude écologique de cas de légionellose diagnostiqués au Tessin pendant l'été 2005, cartographie et contrôle microbiologique des tours de refroidissement [master thesis]. Switzerland: Université Genève, 2005. 